http://doi.org/10.35784/iapgos.1569

\title{
AN OVERVIEW OF CLASSIFICATION METHODS FROM DERMOSCOPY IMAGES IN SKIN LESION DIAGNOSTIC
}

\author{
Magdalena Michalska ${ }^{1}$, Oksana Boyko \\ ${ }^{1}$ Lublin University of Technology, Department of Electronics and Information Technology, Lublin, Poland, ${ }^{2}$ Danylo Halytsky Lviv National Medical University, Department of \\ Medical Informatics, Lviv, Ukraine
}

Abstract. The article contains a review of selected classification methods of dermatoscopic images with human skin lesions, taking into account various stages of dermatological disease. The described algorithms are widely used in the diagnosis of skin lesions, such as artificial neural networks (CNN, DCNN), random forests, SVM, kNN classifier, AdaBoost MC and their modifications. The effectiveness, specificity and accuracy of classifications based on the same data sets were also compared and analyzed.

Keywords: dermatoscopic images, classification methods, neural networks, SVM, skin cancer, skin lesions

\section{PRZEGLAD METOD KLASYFIKACJI OBRAZÓW DERMATOSKOPOWYCH WYKORZYSTYWANYCH W DIAGNOSTYCE ZMIAN SKÓRNYCH}

Streszczenie. Artykut zawiera przegląd wybranych metod klasyfikacji obrazów dermatoskopowych zmian skórnych człowieka z uwzględnieniem różnych etapów choroby dermatologicznej. Opisane algorytmy sa szeroko wykorzystywane $w$ diagnostyce zmian skórnych, takie jak sztuczne sieci neuronowe $(C N N, D C N N)$, random forests, SVM, klasyfikator kNN, AdaBoost MC i ich modyfikacje. Porównana i przeanalizowana została również skuteczność, specyficznośc i dokładność klasyfikatów w oparciu o te same zestawy danych.

Słowa kluczowe: obrazy dermatoskopowe, metody klasyfikacji, sztuczne sieci neuronowe, SVM, nowotwór skóry, zmiany skórne

\section{Introduction}

Nowadays, the classical classification methods of dermatoscopic images used by generations of doctors are becoming insufficient. These include the ABCD, Hunter, Menzies method [25], 7-point checklist [4], TDS, Chaos-Clue [29], scale Glasgow, scale Hunter and many others [3, 7, 22]. They do not allow to effectively diagnose cancer and save human health and even life [5].

Classic pattern analysis gives the opportunity to describe skin lesions for diagnostic purposes, five basic elements are enough: lines, circles, pseudopodia, papules and dots. Each of these elements can be part of the pattern. To create a pattern, it is necessary to repeat the same structure multiple times. The presence of specific colors and the number of colors is of great importance in dermatoscopy. The Hunter scale gives a score in the range of zero to thirteen points. Clinical symptoms suggesting suspected melanoma are often grouped in two systems: the ABCD scale and the seven-point Glasgow scale. Chaos - Clue is a simple method for quickly assessing suspected pigmented skin lesions with a dermatoscopy. Its use can lead to a better diagnosis of melanoma and other skin cancers [29]. Figure 1 presents the most important stages of this algorithm.

Therefore, automated diagnostic systems have been developed to assist doctors in the diagnostic process. The images used in programs are subjected to the process of removing artifacts, segmentation of changes, extraction of features, optimization and finally classification of the skin lesions. Most often, the lesions is characterized by the type of damage, color, arrangement, shape, texture and border irregularity. Currently, the classification of skin lesions uses automatic recognition of lesions or known anomalies occurring in a given population. These methods are also intended to classify a given birthmark as a pattern with a colored texture.

Classification means that elements of set $X=\left\{f x_{1}, x_{2}, \ldots, x_{n}\right\}$ are assigned elements of set $Y=\left\{\begin{array}{llll}f y_{1}, & y_{2}, \ldots, & y_{n}\end{array}\right\}$, for $i=1, \ldots, n$, where $n$ is a number of objects. The set $X$ is called the set of feature vectors $x_{i}$, but $Y$ is a set of classes $y_{i . .}$ The classifier construction process consists of preparation of learning data, test subset, classification and calculation of classification efficiency.

One of the first ways to classify was discriminant analysis [18]. Next appeared artificial neural networks (ANNs) [14, 20], decision trees [21], support vector machine (SVM) [11, 12], logistic regression [8], ensemble learners [2, 30]. Many different classifiers have been used to classify dermatoscopic skin images. Skin melanoma is classified using kNN classifier [9]. The AdaBoost MC algorithm [1] is considered optimal and reliable.

The types of machine learning algorithms are commonly divided into 4 categories: supervised learning, unsupervised learning, semi-supervised learning and reinforcement learning. The mostly common supervised learning algorithms are nearest neighbor, naive Bayes, decision trees, linear regression, logistic regression, linear discriminant analysis, SVM, neural networks, similarity learning. Algorithms try to model relationships and dependencies between the target prediction output and the input features. They predict the output values for new data based on those relationships which it learned from the previous data sets.

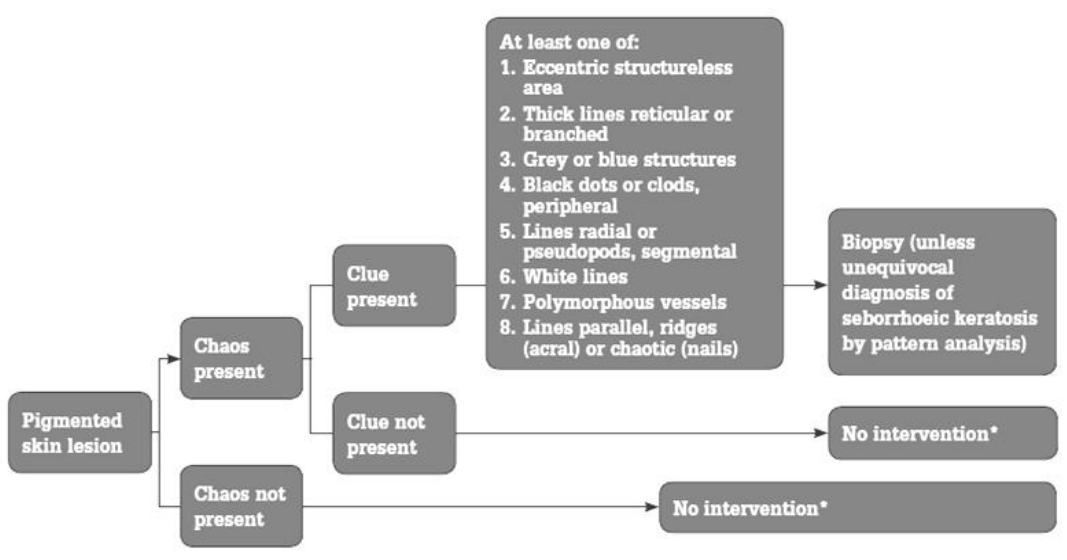


The most current methods in the field of melanoma classification use artificial neural networks of increasingly complex structure. The most commonly used include artificial neural networks, logistic regression, decision making using trees and supervised machine learning algorithms.

\section{Supervised machine learning algorithm in classification}

Support Vector Machines (SVM) is supervised learning model with associated learning algorithm. SVM is most commonly used in classification problems [27, 31]. In the algorithm, each data element is a point in $\mathrm{n}$-dimensional space (where $\mathrm{n}$ is the number of features), the value of each feature is a coordinate value. Then elements classification is performed by finding the hyperplane, which differentiates on the best way two classes. The optimal separating hyperplane (OSH) is a hyperplane which margins are the largest.

In [31] the proposed classification model uses HSV, LBP and HOG functions, that are passed to the SVM classifier. The function extraction process has been divided into three parts, features of color, texture and shape of melanoma. Then the feature vector of all these three features was joined to obtain a complex feature vector. The process is repeated for all images in the data set and vector features are marked according to their accepted classes. The labeled feature vectors are fed to the SVM classifier to effectively train the algorithm. In tests, all functions are extracted from the new image and the feature vector is fed to SVM to predict classes. The scheme of described activities is presented in Figure 2.

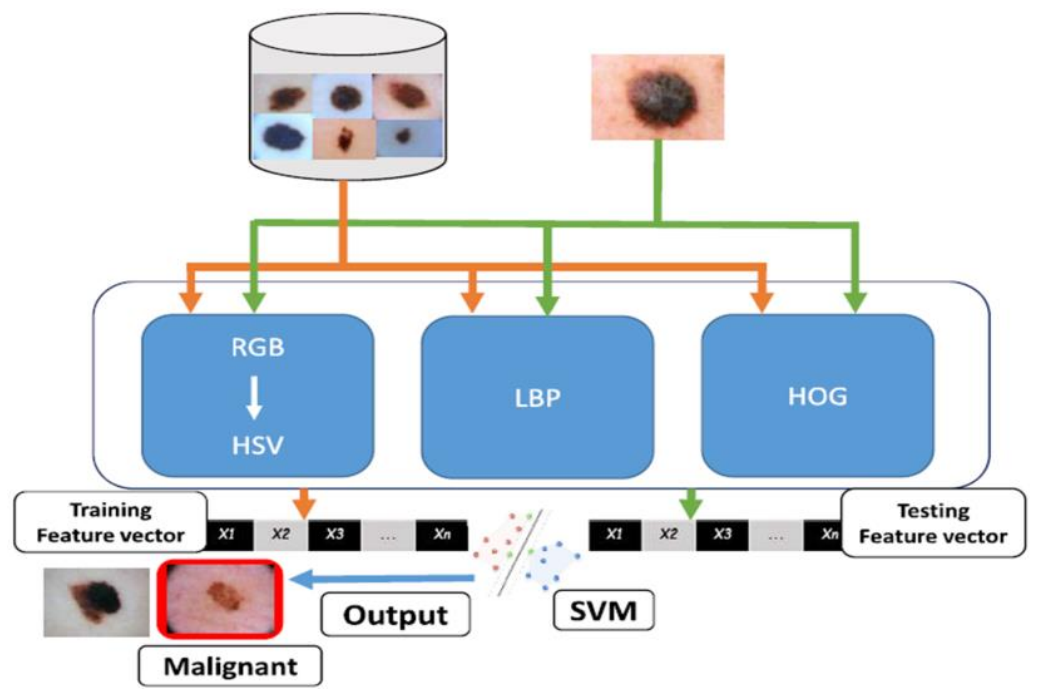

Fig. 2. Diagram of activities using SVM in the classification of dermatoscopic images [31]

\section{Classifiers based on Convolutional Neural Network (CNN)}

Neural networks are used in many fields of computer science, especially in image processing. Nowadays, various modifications are becoming more and more common. They are used to classify images [15, 17, 23, 31, 33].

More and more scientists are comparing skin diseases diagnostics effectiveness of computer algorithms with experienced doctors. Classification of skin lesions enabling identification of the most common tumors using CNN was used in [16]. The network was trained directly from a data set containing over 129,000 clinical images, using only pixels and skin disease labels as input.

The effects have been compared with the diagnoses of over 20 dermatologists. The doctor's diagnoses were confirmed by an additional skin lesion biopsy. The diagnosed cases were malignant melanomas and benign skin birthmarks. CNN achieves performance comparable to that of expert dermatologists, 22 and 21 experienced doctors participated in the study. Figure 2 demonstrates artificial intelligence possibilities in classification of skin cancer comparable to dermatologists. The charts include results of physician diagnostics and algorithm for 130 melanoma images and 111 dermatoscopic images. The average of dermatologists was also included. It turns out that when diagnosing melanoma, doctors have comparable diagnostic effectiveness to the proposed algorithm. In contrast, their diagnostic ability decreases for dermal pictures containing various stages of skin diseases.

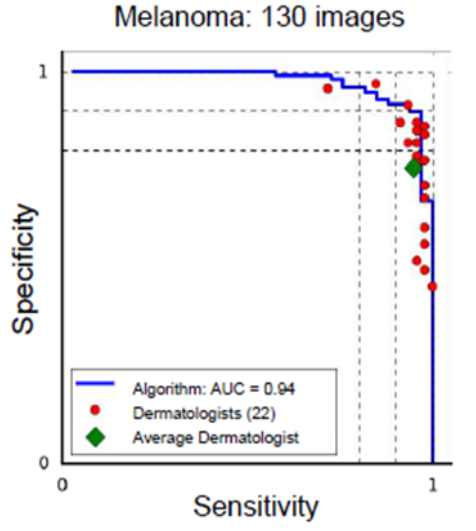

Melanoma: 111 dermoscopy images

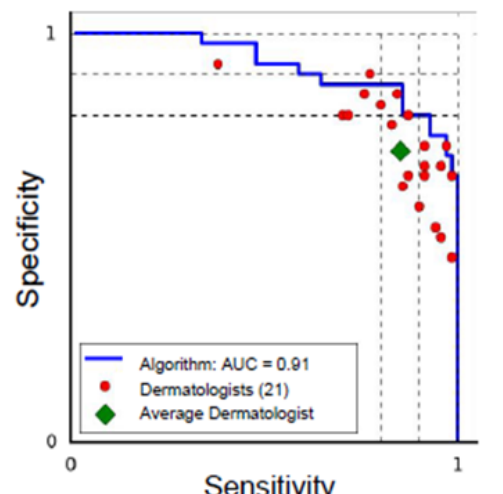

(B)

Sensitivity 


\section{Classifiers based on Deep Convolutional Neural Networks (DCNN)}

Neural networks different models modifications are increasingly common. They contain deep learning algorithms [13], deep convolutional neural networks (VGGNet convolutional neural network architecture and the transfer learning paradigm) [28], synergic deep learning (SDL). They show great effectiveness in the diagnosis of skin lesions.

In [34] was proposed a model combining synergistic models (SDL) and (DCNN). The proposed model (Figure 4) consists of three modules: an input layer, double DCNN-A/B components and synergistic network. The input layer takes a few images as input. Each DCNN component is for self-study under the supervision of class labels. The synergistic network checks if the pair of input images belongs to the same category and provides feedback.

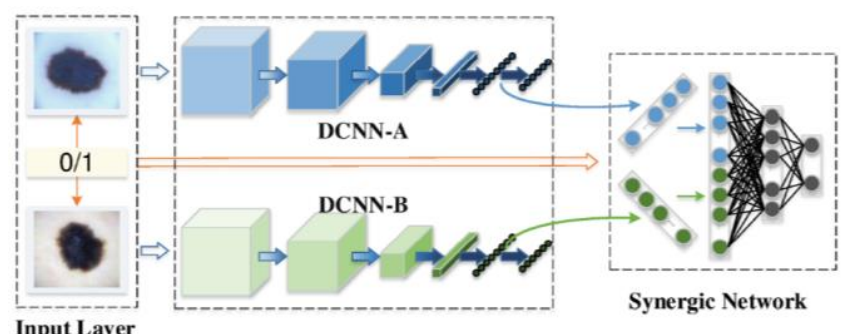

Fig. 4. Proposed model architecture of constructed input layer, double DCNN components $(D C N N-A / B)$ and synergic network [34]

\section{Effectiveness of selected classification methods}

Many scientists $[6,10,19,24,26,32]$ test the effectiveness of available or modified classifiers on various dermatoscopic data. For they research, scientits use a large number of dermatoscopic images using many new modifiers of classifiers.

Figure 5 presents ROC curves (Receiver Operationg Characteristic), which are the tool for joint assessment of the classifier, its sensitivity and specificity. It included AdaBoost MC, ML - SVM, ML - KNN algorithms. The larger area under the ROC curve usually allows for more accurate classification of objects.

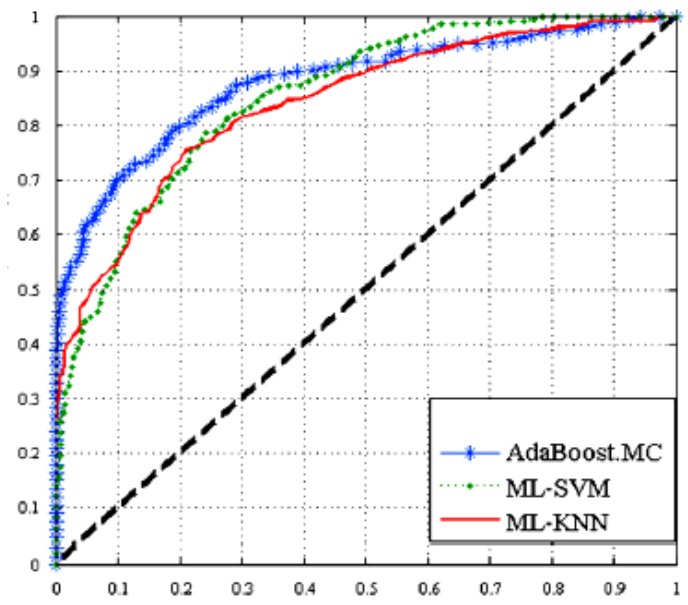

Fig. 5. ROC curves for AdaBoost MC, ML-SVM, ML- KNN algorithms [1]

It is important that the classification algorithms are tested on the same data sets. For this reason, many publications are cited that use different data sets to compare the classifier. Table 1 compares the classifications based on the two models Caucasians (1) and Xanthou (2). Random forests and KNN algorithms showed a specificity above $96 \%$.
Table 1. Results of classifiers based on different models [32]

\begin{tabular}{|l|c|c|c|c|c|c|}
\hline \multirow{2}{*}{ Classifiers } & \multicolumn{2}{|c|}{$\begin{array}{c}\text { Sensitivity } \\
(\mathbf{\%})\end{array}$} & \multicolumn{2}{c|}{$\begin{array}{c}\text { Specificity } \\
(\mathbf{\%})\end{array}$} & \multicolumn{2}{c|}{$\begin{array}{c}\text { Accuracy } \\
(\boldsymbol{\%})\end{array}$} \\
\cline { 2 - 7 } & $\mathbf{1}$ & $\mathbf{2}$ & $\mathbf{1}$ & $\mathbf{2}$ & $\mathbf{1}$ & $\mathbf{2}$ \\
\hline Random forests & 73.33 & 80.00 & 95.83 & $\mathbf{9 6 . 2 5}$ & 88.33 & 90.83 \\
\hline KNN & 51.67 & 77.50 & $\mathbf{9 7 . 5 0}$ & $\mathbf{9 6 . 2 5}$ & 82.22 & 90.00 \\
\hline Adaboost & 71.67 & 80.00 & 95.83 & 92.50 & 87.78 & 88.33 \\
\hline RBF SVM & 75.00 & 87.50 & 94.17 & 93.50 & 87.78 & 91.67 \\
\hline S - SVM & 75.00 & 85.00 & 93.33 & 91.25 & 87.22 & 89.17 \\
\hline DCNN & 83.33 & 95.00 & 95.00 & 93.75 & 91.11 & 94.17 \\
\hline
\end{tabular}

At dermatoscopic images are many artifacts, is not easy to use effective classification algorithm. In [1] pattern based on CASH is very accurate. Skin lesions were classified by pattern detectors classes such as reticular, globural, homogeneous, parallel, cobblestone, starbust, multicomponent. Table 2 presents sensitivity, specificity, accuracy, average standard deviation training error (E) during learning by AdaBoost.MC. Reticular and globural patern detectors have reached a specificity value above $97 \%$ for the dermatoscopic image dataset chosen by scientists.

Table 2. Pattern classification of dermatoscopic lessions made by AdaBoost.MC [1]

\begin{tabular}{|l|c|c|c|c|}
\hline $\begin{array}{c}\text { Patern } \\
\text { detector }\end{array}$ & $\begin{array}{c}\text { Sensitivity } \\
(\mathbf{\%})\end{array}$ & $\begin{array}{c}\text { Specificity } \\
(\mathbf{\%})\end{array}$ & $\mathbf{E}$ & $\begin{array}{c}\text { Accuracy } \\
(\boldsymbol{\%})\end{array}$ \\
\hline reticular & 87.11 & $\mathbf{9 7 . 9 6}$ & 0.459 & 0.981 \\
\hline globural & 86.25 & $\mathbf{9 7 . 2 1}$ & 0.477 & 0.997 \\
\hline cobblestone & 87.76 & 93.23 & 0.555 & 0.990 \\
\hline homogeneous & 90.47 & 95.10 & 0.697 & 0.996 \\
\hline parallel & 85.25 & 89.50 & 0.524 & 0.989 \\
\hline starbust & 89.62 & 90.14 & 0.634 & 0.966 \\
\hline multicomponent & 98.50 & 93.11 & 0.344 & 0.989 \\
\hline
\end{tabular}

In [23] SVM has been compared with the Random algorithm classifier. The best accuracy of class recognition on the database has been achieved in the SVM classifier. SVM associated with attriutes selected by the Fisher method. Scientists have received total accuracy equal to $93.8 \%$ for recognizing melanoma from the other lesions of human skin, sensitivity in recognition of melanoma is equal to $95.2 \%$ and specificity $92.4 \%$.

\section{Discussion and conclusions}

In experiments, verification of extraction, reduction of features, classification, performance was tested using various classifiers. These methods are tested on various data sets from around the world. Experimental results strongly suggest that the proposed classifiers are particularly beneficial in distinguishing between malignant and benign lesions. Any classification problem can be solved with more than one classifier. It is important that they are not hypersensitive to damage lesions, eliminate less important functions, reduce the dimension of the function and choose the optimal set.

An effective algorithm should well minimize the object classification error presented in the image. However, the error cannot be completely eliminated. Image elements or the entire image is classified based on a finite set of its features. To improve classification efficiency, it is important to combine available methods.

Equipped with software with classifiers, mobile devices can potentially extend the scope of diagnosis. It is anticipated that many new algorithms will be created in the future. It is important to provide universal access to the necessary diagnostic care. The classification results provided by the tested models over the years prove to be more accurate in the process of diagnosis of skin lesions. 


\section{References}

[1] Abbas Q., Celebi M.E., Serrano C., Fondo'n Garci' I., Maa G.: Pattern classification of dermoscopy images: A perceptually uniform model. Pattern Recognition 46, 2013, 86-97.

[2] Abedini M., Chen Q., Codella N.C.F., Garnavi R., Sun X.: Accurate and scalable system for automatic detection of malignant melanoma. Dermoscopy Image Analysis. CRC Press, Boca Raton 2015.

[3] Alendar F., Kittler H, Helppikangas H., Alendar T.: Clear definitions,simple terminology, no metaphoric terms. Expert Rev. Dermatol. 3, 2008, 27-29.

[4] Argenziano G., Fabbrocini G., Carli P., De Giorgi V., Sammarco E., Delfino M. Epiluminescence microscopy for the diagnosis of doubtful melanocytic skin lesions, comparison of the $\mathrm{ABCD}$ rule of dermatoscopy and a new 7-poin checklist based on pattern analysis. Archives of Dermatology 134, 1998, 15631570

[5] Argenziano G., Soyer H.P., Chimenti S., Talamini R., Corona R., Sera F. Dermoscopy of pigmented skin lesions: results of a consensus meeting via the Internet. Journal of American Academy of Dermatology 48(5), 2003, 679-693.

[6] Barata, C., Ruela, M.: Two Systems for the detection of melanomas in dermoscopy images using texture and color features. IEEE Systems Journal 8(3), 2014, 965-979.

[7] Blum H., Ellwanger U.: Digital image analysis for diagnosis of cutaneous melanoma, development of a highly effective computer algorithm based on analysis of 837 melanocytic lesions. British Journal of Dermatology 151(5), 2004, 1029-1038.

[8] Blum H., Luedtke H., Ellwanger U., Schwabe R., Rassner G., Garbe C.: Digita image analysis for diagnosis of cutaneous melanoma, development of a highly effective computer algorithm based on analysis of 837 melanocytic lesions Computerized Medical Imaging and Graphics 31(6), 2007, 362-373.

[9] Burroni M., Corona R, Dell'Eva G., Sera F. Melanoma computer -aided diagnosis reliability and feasibility study. Clinical Cancer Research 10(6), 2004 1881-1886.

[10] Celebi M.E., Aslandogan Y.A., Stoecker W.V., Iyatomi H., Oka H., Chen X. Unsupervised border detection in dermoscopy images. Skin Res Technol. 13, 2007, 1-9.

[11] Celebi M. E., Kingravi H.A., Uddin B., Iyatomi H., Aslandogan Y.A., Stoecker W.V., Moss R.H.: A methodological approach to the classification of dermoscopy images. Computerized Medical Imaging and Graphics 31(6), 2007 362-373.

[12] Celebi M.E., Kingravia H.A., Uddina B., Iyatomid H., Aslandogana Y.A. Stoeckerb W.V., Mossc R.H.: A methodological approach to the classification of dermoscopy images. Comput Med Imaging Graph. 31(6), 2007, 362-373.

[13] Codella N., Cai J., Abedini M., Garnavi R., Halpern A., Smith J. R.: Deep learning, sparse coding, and SVM for melanoma recognition in dermoscopy images, Machine Learning in Medical Imaging. Springer, Munich 2015.

[14] Ercal F., Chawla A., Stoecker W.V., Lee H.-C., Moss R.H.: Neural network diagnosis of malignant melanoma from color images. IEEE Transactions on Biomedical Engineering 41(9), 1994, 837-845.

[15] Esteva, A.: Dermatologist-level classification of skin cancer with deep neura networks. Nat. Res. 542(7639), 2017, 115-118

[16] Esteva A., Kuprel B., Novo R.A., Ko J., Swetter S. M., Bla H.M, Thrun S. Dermatologist-level classification of skin cancer with deep neural networks. Nature 542, 2017, 115-118.

[17] Ge Z., Demyanov S., Chakravorty R., Bowling A., Garnavi R.: Skin disease recognition using deep saliency features and multimodal learning of dermoscopy and clinical images. Springer Cham LNCS 10435, 2017, 250-258.

[18] Green A., Martin N., McKenzie G., Pfitzner J., Quintarelli F., Thomas B. W. O'Rourke M., Knight N.: Computer image analysis of pigmented skin lesions, Melanoma research 1(4), 1991, 231-236.

[19] Gutman D., Codella N., Celebi E., Helba B., Marchetti M., Mishra N., Halpern A.: Skin lesion analysis toward melanoma detection: A Challenge at the International Symposium on Biomedical Imaging (ISBI) 2016, International Skin Imaging Collaboration (ISIC). eprint arXiv:1605.01397.

[20] Husemann R., Tölg S., Seelen W.V., Altmeyer P., Frosch P.J., Stücker M., Hoffmann K., El-Gammal S.: Computerised diagnosis of skin cancer using neural networks. Skin Cancer and UV Radiation. Springer, Berlin 1997.

[21] Kahofer P., Hofmann-Wellenhof R., Smolle J.: Tissue counter analysis of dermatoscopic images of melanocytic skin tumours: preliminary findings. Melanoma research 12(1), 2002, 71-75.
[22] Kittler H., Riedl E., Rosendahl C., Cameron A.: Dermatoscopy of unpigmented lesions of the skin: A new classification of vessel morphology based on pattern analysis. Dermatopathology: Practical \& Conceptual 14(4), 2018, 3.

[23] Kruk M., Świderski B., Osowski S., Kurek J., Słowińska M., Walecka I.: Melanoma recognition using extended set of descriptors and classifiers. J Image Video Proc. 43, 2015 [https://doi.org/10.1186/s13640-015-0099-9].

[24] Menzies S.W., Bischof L, Talbot H, Gutenev A, Avramidis M, Wong L.: The performance of SolarScan: An automated dermoscopy image analysis instrument for the diagnosis of primary melanoma. Arch Dermatol. 141(11) 2005, 1388-1396.

[25] Menzies S., Ingvar C., Crotty K., McCarthy W.: Frequency and morphologic characteristics of invasive melanomas lacking specific surface microscopic features. Archives of Dermatology 132, 1996, 1178-1182.

[26] Michalska M.: Klasyfikacja zmian skórnych z obrazów dermatoskopwych, Wybrane zagadnienia $\mathrm{z}$ zakresu elektrotechniki, inżynierii biomedycznej budownictwa. Prace doktorantów Politechniki Lubelskiej 2019, 108-120.

[27] Piątkowska W., Martyna J., Nowak L.: A decision support system based on the semantic analysis of melanoma images using multi-elitist PSO and SVM. Proceedings of the 7th International Conference on Machine Learning and Data Mining in Pattern Recognition MLDM'11 1, 2011, 362-374.

[28] Romero-Lopez A., Giro-i-Nieto X., Burdick J., Marques O. Skin lesion classification from dermoscopic images using deep learning techniques. Proc. of Biomedical Engineering 2017 [https://doi.org/10.2316/P.2017.852-053].

[29] Rosendahl C., Cameron A., McColl I., Wilkinson I.: Dermatoscopy in routine practice. Chaos and Clues. Australian Family Physician 41(7), 2012

[30] Schaefer G., Krawczyk B., Celebi M.E., Iyatomi H.: An ensemble classification approach for melanoma diagnosis, Memetic Computing 6(4), 2014, 233-240.

[31] Shahid M., Khan S.: Dermoscopy images classification based on color, texture and shape features using SVM. The 3rd International Conference on Next Generation Computing (INC GC2017b), 243-245.

[32] Xie F., Fan H., Li Y., Jiang Z., Meng R., Bovik A.: Melanoma classification on dermoscopy images using a neural network ensemble model. IEEE Transationa on Medical Imaging 36(3), 2017, 849-858.

[33] Yu L., Chen H., Dou,Q., Qin J., Heng P.A.: Automated melanoma recognition in dermoscopy images via very deep residual networks. IEEE Trans. Med. Imaging 36(4), 2017, 994-1004.

[34] Zhang J., Xie Y., Wu Q., Xia Y.: Skin lesion classification in dermoscopy images using synergic deep learning. Springer Nature Switzerland, LNCS $11071,2018,12-20$

\section{M.Sc. Magdalena Michalska}

e-mail: magdalena.michalska@pollub.edu.pl

Ph.D. student at Lublin University of Technology Recent graduate Warsaw University of Technology The Faculty Electronics and Information Technology. Her research interests include medical image processing, 3D modelling, optoelectronics, spectrophotometry. Author of more than 10 publications.

http://orcid.org/0000-0002-0874-3285

\section{Dr. Tech. Sc. Oksana Boyko}

e-mail: oxana_bojko@ukr.net

Oksana Boyko graduated from Lviv Polytechnic State University with a master's degree in Applie Mathematics. Since 2011 she is the Head of the Medical Informatics Department of Danylo Halytsky Lviv National Medical University.

Her research interests include mathematical modelling, biomedical sensors and embedded systems, medical information systems. She is the author of ove 200 scientific and methodological works.

http://orcid.org/0000-0002-8810-8969
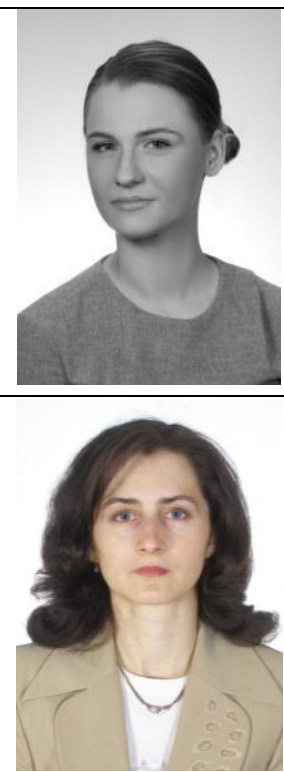

otrzymano/received: 22.03 .2020

przyjęto do druku/accepted: 26.06 .2020 